\title{
Erratum to: Transcriptional regulation, stabilization, and subcellular redistribution of multidrug resistance-associated protein 1 (MRP1) by glycogen synthase kinase 3 $\alpha \beta$ : novel insights on modes of cadmium-induced cell death stimulated by MRP1
}

\author{
Hak-Ryul Kim · Kang-Yo Lee $\cdot$ Sang-Gun Ahn · \\ Byung-Hoon Lee $\cdot$ Ki-Tae Jung $\cdot$ Jung-Hoon Yoon $\cdot$ \\ Hyo-Eun Yoon $\cdot$ Seon-Hee Oh
}

Published online: 29 January 2015

(C) Springer-Verlag Berlin Heidelberg 2015

\section{Erratum to: Arch Toxicol}

DOI 10.1007/s00204-014-1381-9

In the original publication of the article, the second author name was incorrectly spelled in the author group. The name should be Kang-Yo Lee.

The online version of the original article can be found under doi:10.1007/s00204-014-1381-9.

H.-R. Kim

Department of Internal Medicine, Wonkwang University School of Medicine, Iksan 570-749, Korea

\section{K.-Y. Lee · B.-H. Lee}

College of Pharmacy and Research Institute of Pharmaceutical

Sciences, Seoul National University, Seoul 151-742, Korea

S.-G. Ahn · H.-E. Yoon

Department of Pathology, College of Dentistry, Chosun

University, Gwangju 501-759, Korea

\section{K.-T. Jung}

Department of Anesthesiology and Pain Medicine, School

of Medicine, Chosun University, Gwangju 501-759, Korea

J.-H. Yoon

Department of Oral and Maxillofacial Pathology, Daejeon Dental Hospital, College of Dentistry, Wonkwang Bone Regeneration Research Institute, Wonkwang University, Daejeon 302-120,

Korea

S.-H. Oh $(\bowtie)$

The Division of Natural Medical Sciences, College of Health

Science, Chosun University, Seosuk-dong, Dong-gu,

Gwangju 501-759, Korea

e-mail: seonh@chosun.ac.kr 